\title{
Gastroprotective effects of nebivolol and simvastatin against cold restraint stress- induced gastric ulcer in rats
}

\author{
Samaa Samir Kamar ${ }^{1}$, Noha Samir Abdel Latif ${ }^{2}$, Mohamed Fathi Mohamed Elrefai, ${ }^{3,4}$ \\ Shaimaa Nasr Amin ${ }^{3,5}$ \\ ${ }^{1}$ Department of Histology, Faculty of Medicine, Cairo University, Cairo, Egypt, ${ }^{2}$ Department of Medical Pharmacology, Faculty of Medicine, Cairo \\ University, Cairo, Egypt, ${ }^{3}$ Department of Basic Medical Sciences, Faculty of Medicine, Hashemite University, Zarqaa, Jordan, ${ }^{4}$ Department of Anatomy, \\ Faculty of Medicine, Ain Shams University, Cairo, Egypt, ${ }^{5}$ Department of Medical Physiology, Faculty of Medicine, Cairo University, Cairo, Egypt
}

\begin{abstract}
Gastric ulcer is one of the most serious diseases. Nebivolol (Neb), a $\beta 1$-blocker, exhibits vasodilator and antioxidative properties, simvastatin (Sim) antihyperlipidemic drug, exhibits anti-oxidative, anti-inflammatory properties and promote endogenous nitric oxide (NO) production. The aim of this study was to evaluate the gastroprotective effects of Neb and Sim against cold restraint stress (CRS)-induced gastric ulcer in rats. Rats were restrained, and maintained at $4^{\circ} \mathrm{C}$ for 3 hours. Animals were divided into six groups; control group, CRS group, and four treatment groups received ranitidine (Ran), $\mathrm{Neb}$, Sim and both Neb and Sim. Treatments were given orally on a daily basis for 7 days prior to CRS. The gastroprotective effects of Neb and Sim were assessed biochemically by measuring variations in prostaglandins E2, NO, reduced glutathione and malondialdehyde, and functionally by estimating force of contractions of isolated rat fundus in the studied groups in response to acetylecholine stimulation and morphologically using hematoxylin and eosin staining, periodic acid Schiff's reaction and immunohistochemistry for cyclooxygenase 2 in gastric mucosa. CRS caused significant ulcerogenic effect. Alternatively, pretreatment with Ran, Neb, and Sim significantly corrected biochemical findings, pharmacological and histological studies.
\end{abstract}

Key words: Gastric ulcer, Cold restraint stress, Ranitidine, Nebivolol, Simvastatin

Received March 14, 2020; Revised May 6, 2020; Accepted June 24, 2020

\section{Introduction}

Gastric ulcer is an illness that affects a considerable number of people worldwide [1]. It occurs at a site where the mucosa epithelium is exposed to aggressive factors such as

Corresponding author:

Shaimaa Nasr Amin (iD

Department of Basic Medical Sciences, Faculty of Medicine, Hashemite University, Zarqaa 13133, Jordan

Department of Medical Physiology, Faculty of Medicine, Cairo University, Cairo 11451, Egypt

E-mail: shaimaa599@yahoo.com acid and pepsin $[2,3]$. The pathophysiology of gastric ulcer has generally focused on imbalance between aggressive and protective factors in the stomach [4], such as acid-pepsin secretion, parietal cell, mucosal barrier, mucus secretion, blood flow, cellular regeneration and endogenous protective agents; prostaglandins (PGs) and epidermal growth factors [5]. Under normal conditions, the integrity of the stomach mucosal barrier is maintained by equilibrium between irritation and defensive factors [6].

The major causes of peptic ulcer disease are - stress, chronic use of non-steroidal anti-inflammatory drugs, alcohol, cigarette smoking, genetic predisposition, diet, and Helicobacter pylori [5]. The contribution of gastric neutro-

\section{Copyright ( 2020 . Anatomy \& Cell Biology}

This is an Open Access article distributed under the terms of the Creative Commons Attribution Non-Commercial License (http://creativecommons.org/licenses/by-nc/4.0/) which permits unrestricted non-commercial use, distribution, and reproduction in any medium, provided the original work is properly cited. 
phil accumulation, inflammatory cytokine production, free radical production, decreased antioxidants and decreased mucosal blood flow have been reported to be involved in the pathogenesis of stress-induced gastric lesions [7].

It is well established that nitric oxide (NO) exerts gastroprotective activity mostly due to the maintenance of blood flow around the ulcer [8]. The beneficial effects of NO on wound repair may be attributed to its functional influences on angiogenesis and inflammation [9].

Nebivolol (Neb), a third-generation highly selective $\beta 1$ adrenergic receptor antagonist, causes vasodilatation by stimulating the production of $\mathrm{NO}$ via rapid activation of endothelial and neuronal NO synthase and exhibits anti-oxidant effects by reducing nicotinamide adenine dinucleotide phosphate (NADPH) oxidase-induced superoxide generation $[10,11]$. Neb is well tolerated and does not appear to have adverse effects on lipid metabolism and insulin sensitivity like traditional $\beta$-blockers [12].

Statins are widely used clinically for lowering hypercholesterolemia [13]. Besides the therapeutic use in hyperlipidemia, the antioxidant, anti-inflammatory and immunomodulatory benefits of statins have been reported in many studies [14]. They promote endogenous NO production [15] decrease platelet aggregation and inhibit thromboxane formation [16]. Simvastatin (Sim) which has tested in this study is a commonly prescribed statin with antioxidant and antiinflammatory effects [17].

The present study was conducted to elucidate the possible gastroprotective effect of Neb and Sim pretreatment on stress-induced gastric ulcer in rats and the mechanisms underlying this protection.

\section{Materials and Methods}

The experimental steps, animal handling, sampling and scarification were done according to the Guide for the Care and Use of Laboratory Animals, Eighth edition [18] and were approved by the Ethics and scientific Committee guidelines for animal care and use, Department of Pharmacology, Kasr Al Ainy Faculty of Medicine, Cairo University, Egypt.

\section{Drugs and chemicals}

Sim was obtained from AstraZeneca, England. Neb was obtained from Chemipharma, Egypt and ranitidine (Ran) was obtained from Glaxo, England. All drug solutions and suspensions were freshly prepared.

\section{Animals and study design}

A total of 36 male albino Wistar adult rats with an average weight of $200-250 \mathrm{~g}$ were housed in a temperaturecontrolled room $\left(22^{\circ} \mathrm{C} \pm 1^{\circ} \mathrm{C}\right)$ with a 12 hours light/dark cycle. The animals were divided into 6 groups (each consisting of 6 rats):

Control group: In which the animals received distilled water orally for 7 days. The control group was kept at room temperature without any stress.

Cold restraint stress: Rats were restrained by fixing the four limbs to a wooden board using a quartz-pasted tape and placed in a refrigerator at $4^{\circ} \mathrm{C}$ for 3 hours. The door of the refrigerator was opened every 0.5 hours for inspection and follow-up [19] and maintained for 3 hours [20].

Ranitidine pretreated group: In which animals were pretreated with Ran $50 \mathrm{mg} / \mathrm{kg}$ orally daily by a gastric tube for 7 days then, gastric ulceration was induced by cold restraint stress (CRS) [21].

Simvastatin pretreated group: In which animals were pretreated with $40 \mathrm{mg} / \mathrm{kg}$ Sim orally for 7 days then, gastric ulceration was induced by CRS [22].

Nebivolol pretreated group: In which animals were pretreated with $5 \mathrm{mg} / \mathrm{kg} \mathrm{Neb}$ orally daily for 7 days then, gastric ulceration was induced by CRS [23].

Simvastatin+nebivolol pretreated group: In which animals were pretreated with both Neb orally daily for 7 days then, gastric ulceration was induced by CRS.

Rats were deprived of food for 24 hours prior to the experiment in mesh-bo ttomed cages to minimize coprophagia but allowed free access to water except for the last hour before the experiment. All experiments were performed during the same time of the day to avoid variations due to diurnal rhythms of putative regulators of gastric functions.

All groups received equivalent volumes of the above used vehicles.

\section{In vitro (Isolated rat fundus)}

Rats were euthanized by decapitation and exsanguinated. The stomach was dissected out and strips were cut according to the method described by Vane [24]. The strips were cut up in an organ bath maintained at $37^{\circ} \mathrm{C}$ containing Tyrode solution and bubbled with a gas mixture containing $95 \%$ oxygen-5\% carbon dioxide.

The abdomen was opened along the midline and the gastric fundus was excised and put into a dissecting dish filled with Tyrode solution. The fundus was at first flattened by 
two parallel incision along the great curvature. According to the method of Vane [24], several parallel sections at $1.5 \mathrm{~mm}$ intervals with the great curvature were made in the fundus producing very long and narrow isolated preparations (40 $\mathrm{mm}$ in length and $1.5 \mathrm{~mm}$ in width) containing all the layers of the gastric wall. One end of the preparation was attached to the bottom of the bath, and the other to the lever of an isotonic transducer (T3 isotonic transducer; Palm Bio Science, Los Angeles, CA, USA). All strips were loaded with 1.0 g weight Vane [24].

The experiment was designed to test the effect of different doses of acetylcholine 2, 4 , and $8 \mu \mathrm{cg}$ on the stomach fundus of all rat groups.

\section{Biochemical analysis of gastric mucosa}

\section{Determination of oxidative stress markers}

The gastric mucosa was weighed, minced with scissors, and homogenized using $0.1 \mathrm{M}$ phosphate buffer ( $\mathrm{pH}$ 7.4) $\left(0.000005 \mathrm{~m}^{3}\right.$ for each $\mathrm{g}$ of tissue) in homogenizer. After centrifugation at 2,000-3,000 rpm for 20 minutes, the supernatant was extracted and frizzed in $-80^{\circ} \mathrm{C}$ for later use. Oxidative stress markers were detected in the resultant supernatant of gastric mucosal homogenate. The appropriate kits (Biodiagnostic kits, Biodiagnostic, Giza, Egypt) were used for the determination of malondialdehyde (MDA), the end product of lipid peroxidation [25]. A reaction mixture containing $8.1 \%$ sodium dodecyl sulfate, $20 \%$ acetate buffer ( $\mathrm{pH} 3.5$ ) and $0.8 \%$ thiobarbituric acid (TBA) was mixed well with $0.2 \mathrm{ml}$ of stomach tissue homogenate for 3 minutes and then incubated at $95^{\circ} \mathrm{C}$ for 60 minutes. After cooling with running water, the TBA-reactive substance (MDA) was extracted with $1 \mathrm{ml}$ of $\mathrm{H}_{2} \mathrm{O}$ and $2.5 \mathrm{ml}$ of n-butanol: Pyridine mixture (15:1, v/ v). The upper organic layer containing the MDA, which was produced by lipid peroxidation, was measured at $532 \mathrm{~nm}$.

Reduced glutathione (GSH) level activity was estimated based on the method of Ellman [26] and Habig et al. [27]. The precipitated tissue homogenate was treated with 5,5'-dithiobis-(2-nitrobenzoic acid) reagent. The absorbance was read at $412 \mathrm{~nm}$ and the amount of GSH is expressed as $\mathrm{mmol} / \mathrm{mg}$ mucosal tissue.

\section{Determination of prostaglandin E2 and nitric oxide}

The supernatant was used for determination of prostaglandin $\mathrm{E}_{2}\left(\mathrm{PGE}_{2}\right)$ level by ELISA using $\mathrm{PGE}_{2}$ immunoassay kit (R\&D systems, Minneapolis, MN, USA). It was assessed according to the method of Hamberg and Samuelsson [28]. Based on the competitive binding technique in which $\mathrm{PGE}_{2}$ present in a sample competes with a fixed amount of horseradish peroxidase-labeled $\mathrm{PGE}_{2}$ for sites on a monoclonal antibody.

NO measurement is difficult because of its brief half-life. Therefore, nitrate/nitrite levels, which are stable degradation products of NO metabolism, were used as markers. It was quantified in gastric mucosal homogenate using commercial kits (Biodiagnostic) according to the method described by Miranda et al. [29]. A $100 \mathrm{l}$ of the supernatant was mixed with 1001 Griess reagent (0.1\% N-(1-naphthyl) ethylenediamide dihydrochloride, $1 \%$ sulfanilamide in $5 \%$ phosphoric acid) and after 10 minutes the absorbance was measured at $540 \mathrm{~nm}$. The standard curve was obtained by using sodium nitrite.

\section{Histopathological evaluation}

The tissue specimens from the fundic region of the stomach were fixed in $10 \%$ formalin solution for 24 hours. Paraffin blocks were processed and serial $5 \mu \mathrm{m}$-thick sections were obtained and subjected to hematoxylin and eosin (H\&E) for demonstration of structural morphology, and periodic acid Schiff's (PAS) reaction to evaluate the gastric mucosal glycoprotein synthesis.

\section{Immunohistochemistry}

Immunohistochemical staining for cyclooxygenase 2 (COX-2) was performed as it is considered a pivotal mediator for gastric mucosal healing [30]. Rabbit polycolonal antiCOX-2 antibody (Ab) (Thermo scientific cat. \# RB-9072-R7; Thermo Scientific, Waltham, MA, USA) was used. Sections of $5 \mu \mathrm{m}$ thickness were cut from paraffin blocks, deparaffinized, rehydrated and microwaved in citrate buffer, $\mathrm{pH} 6.0$ for 10 minute followed by cooling at room temperature for 20 minutes for antigen retrieval. Quenching of endogenous peroxidase activity was performed. The sections were incubated with the primary Ab against COX-2 (1:200 dilution) and stained as regard to the avidin-biotin complex method using a UltraVision LP Detection. The sections were counterstained with Meyer's haematoxylin to visualize the nucleus.

\section{Morphometry analysis}

Using 'Leica Qwin 500 C' image analyzer (Cambridge, $\mathrm{UK})$, assessment of the area percent (\%) of PAS positive reaction and COX-2 positive (+ve) immunostaining were accom- 
plished. The measures were taken in 10 non overlapping high power fields $(\times 400) /$ rat.

\section{Statistical analysis}

Data were coded and entered using the IBM SPSS Statistics for Windows, Version 21.0 (IBM Co., Armonk, NY, USA). Data was summarized using mean and standard deviation. Comparisons between groups were done using analysis of variance (ANOVA) with multiple comparisons post hoc Benferoni test. The $P$-values $\leq 0.05$ were considered as statistically significant [31].

\section{Results}

\section{Concentration response of isolated rat fundus to acetylcholine}

As shown in Fig. 1, 2: there is significant decrease of acetyl choline induced gastric contraction in CRS compared to control group. Pretreatment with Ran, Sim, nebivolo or combined Sim and Neb significantly increased the force of gastric contraction compared to CRS group. Pretreatment with Ran or combined Sim and Neb achieved the best results which reflect good healing and viability of gastric tissue, however none of the given drugs could increase the force of gastric contraction to normal value measured in the control group.

\section{Biochemical measurement}

Table 1 demonstrates the following: there is significant increase $(P$-value $\leq 0.05)$ in MDA in CRS group compared to control group. Pretreatment with Ran, Sim, nebivolo or combined Sim and Neb significantly decreased gastric MDA compared to CRS group, however with all the given drugs gastric MDA was significantly increased $(P$-value $\leq 0.05)$ compared to control group.

CRS group showed significant decrease $(P$-value $\leq 0.05)$ in gastric GSH, $\mathrm{PGE}_{2}$, and $\mathrm{NO}$ compared to control group. Pretreatment with Ran, Sim, nebivolo or combined Sim and $\mathrm{Neb}$ significantly increased the gastric content for GSH, $\mathrm{PGE}_{2}$ and $\mathrm{NO}$ compared to CRS group.

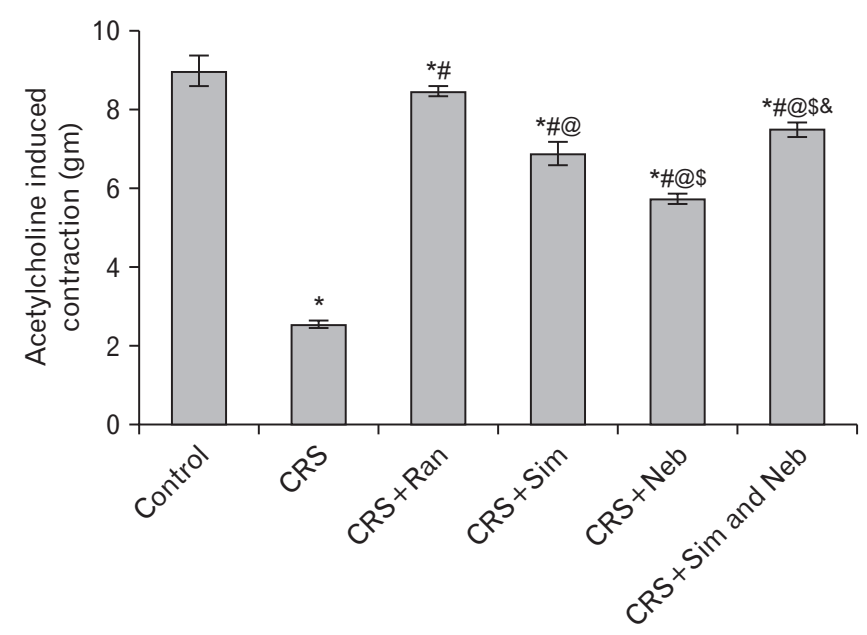

Fig. 2. Comparison of Mean \pm SD of contraction force generated by acetyle choline stimulation in different studied groups. CRS, cold restraint stress; Neb, nebivolol; Ran, ranitidine; Sim, simvastatin. *Significant compared to Control group at $P$-value $\leq 0.05 ;{ }^{*}$ Significant compared to CRS group at $P$-value $\leq 0.05 ;{ }^{\circledR}$ Significant compared to CRS+Ran group at $P$-value $\leq 0.05 ;{ }^{\$}$ Significant compared to CRS+Sim group at $P$-value $\leq 0.05 ;{ }^{8}$ Significant compared to CRS + Neb group at $P$-value $\leq 0.05$.

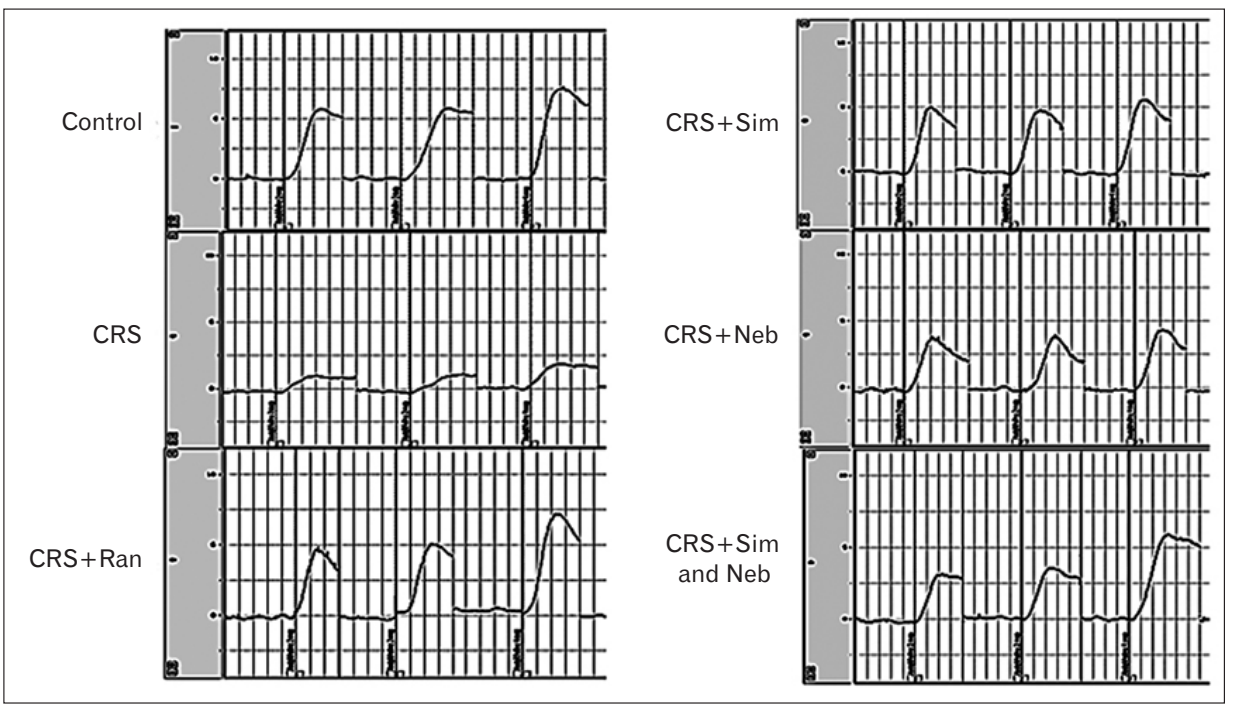

Fig. 1. Force of contractions in the studied groups in response to acetylecholine stimulation. CRS, cold restraint stress; Neb, nebivolol; Ran, ranitidine; Sim, simvastatin. 
Combined Sim and Neb had the best outcome in all measured parameters in the stomach and it normalized the level of NO.

\section{Histopathological results}

H\&E stained gastric mucosal sections of cold restrain group demonstrated multiple mucosal abrasions, hemorrhagic ulcers, and disturbed glandular arrangement. Ranpre-treatment provided complete protection of the gastric mucosa. Administration of either Sim or Neb alone ameliorated the mucosal injury. Meanwhile, combined Sim and
Neb pretreatment substantially protected the gastric mucosa against aberration and ulceration provided with intact mucosa and surface mucus layer covering the gastric pits (Fig. 3).

PAS stained mucosal sections of CRS group displayed areas of absent or little PAS+ve reaction. Ran+CRS exhibited continuous strong PAS+ve reaction. Pretreatment with Sim or Neb provided partial increase in the mucosal PAS+ve reaction provided with significant increase in the area \% of $\mathrm{PAS}+\mathrm{ve}$ reaction compared to CRS group. $\mathrm{Sim}+\mathrm{Neb}+\mathrm{CRS}$ augmented the mucosal PAS+ve reaction which was comparable to control (Fig. 4, 5).

Table 1. Biochemical parameters measured in the stomach of the studied groups

\begin{tabular}{|c|c|c|c|c|c|c|}
\hline Parameter & Control & CRS & CRS+Ran & CRS+Sim & $\mathrm{CRS}+\mathrm{Neb}$ & $\mathrm{CRS}+\mathrm{Sim}$ and $\mathrm{Neb}$ \\
\hline MDA (nmol/mg protein) & $1.25 \pm 0.0498$ & $12.73 \pm 0.35^{\star}$ & $5.173 \pm 0.102^{\star \#}$ & $4.235 \pm 0.079^{* \# @ ~}$ & $3.608 \pm 0.075^{\star \# @ ~}$ & $2.197 \pm 0.069^{\star \# @ \$ \&}$ \\
\hline GSH (mmol/mg protein) & $58.8 \pm 1.544$ & $20.54 \pm 0.845^{\star}$ & $31.92 \pm 0.8264^{\star \#}$ & $43.81 \pm 1.529^{* \# @ ~}$ & $44.067 \pm 1.344^{\star \# @ ~}$ & $49.43 \pm 1.801^{\text {*\$\$\& }}$ \\
\hline $\mathrm{PGE}_{2}$ (pg/mg protein) & $380.75 \pm 7.574$ & $124.31 \pm 3.401^{\star}$ & $260 \pm 6.164^{* *}$ & $188.33 \pm 4.633^{* @}$ & $186.31 \pm 3.237^{\star \# @ ~}$ & $192.5 \pm 5.683^{* \# @ ~}$ \\
\hline $\mathrm{NO}$ (mmol/mg protein) & $2.32 \pm 0.047$ & $0.475 \pm 0.018^{\star}$ & $2.025 \pm 0.058^{\star \#}$ & $2.255 \pm 0.050^{* \# @ ~}$ & $2.193 \pm 0.025^{\star @}$ & $2.335 \pm 0.045^{\# @ \& ~}$ \\
\hline
\end{tabular}

Values are presented as mean \pm SD. CRS, cold restraint stress; Ran, ranitidine; Sim, simvastatin; Neb, nebivolol; MDA, malondialdehyde; GSH, glutathione; PGE 2 , prostaglandin E2; NO, nitric oxide. ${ }^{*}$ Significant compared to Control group at $P$-value $\leq 0.05 ;{ }^{*}$ Significant compared to CRS group at $P$-value $\leq 0.05$; ${ }^{\circledR}$ Significant compared to CRS+Ran group at $P$-value $\leq 0.05$; ${ }^{\text {s }}$ Significant compared to $\mathrm{CRS}+\mathrm{Sim}$ group at $P$-value $\leq 0.05$; ${ }^{8}$ Significant compared to CRS+Neb group at $P$-value $\leq 0.05$.
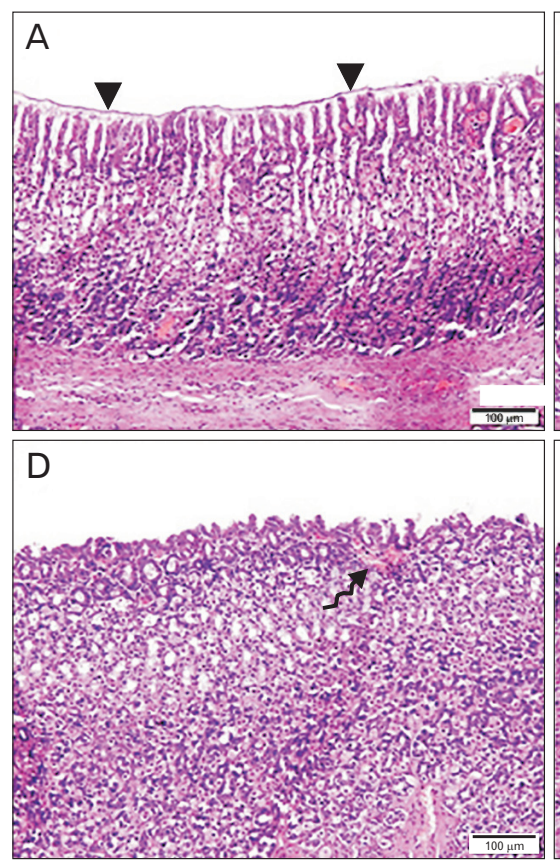
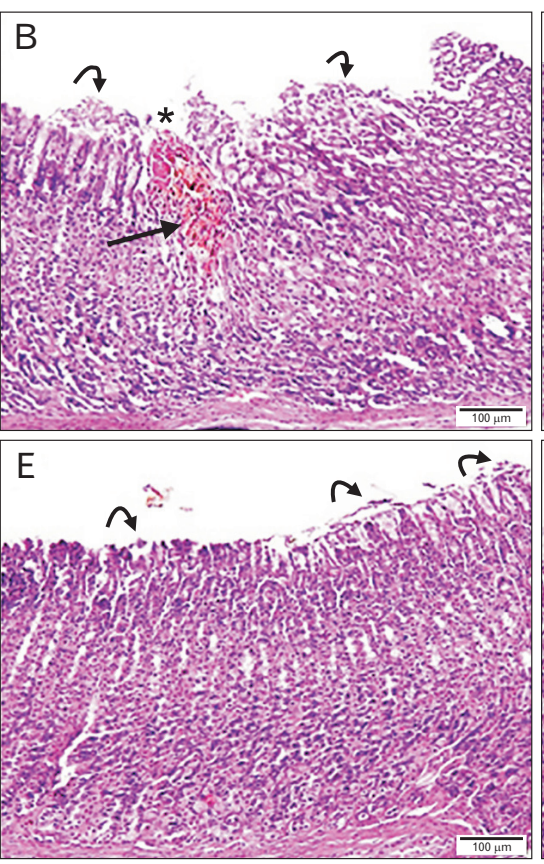
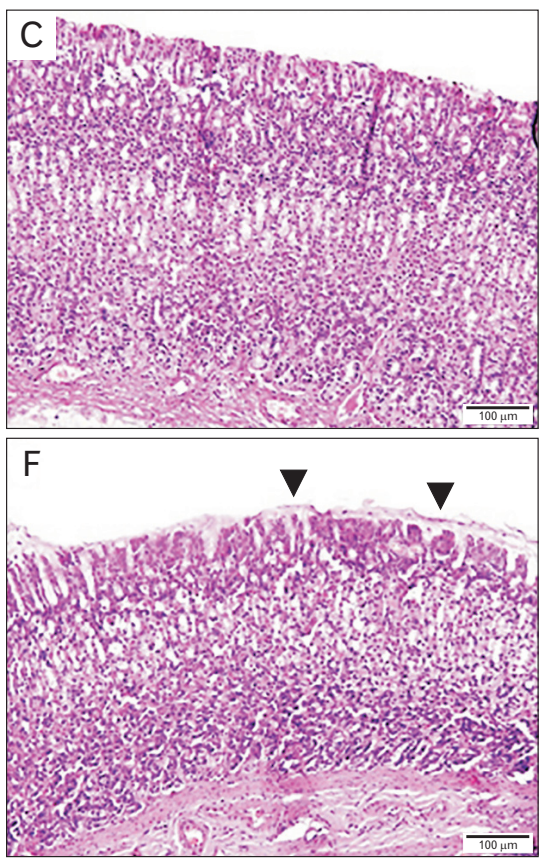

Fig. 3. Photomicrograph of H\&E stained sections in gastric mucosa $(\times 100)$ showing: (A) Control group: intact mucosa with surface mucus layer (arrowheads) covering the gastric pits, gastric glands. (B) CRS group: diffuse mucosal abrasions, hemorrhage (asterisk), hemosiderin precipitation (arrow), patches of sloughed mucosal epithelium (curved arrows) and disturbed glands. (C) Ran+CRS group: intact gastric mucosa with intact surface epithelium. (D) Sim+CRS group: intact gastric mucosa with mild congestion in the lamina propria (curved arrow). (E) Neb+CRS group: ameliorated mucosal erosion with slight disturbance in the surface and cell desquamation (curved arrows). (F) Sim+Neb+CRS group: intact gastric mucosa with surface mucus layer (arrowheads) covering the gastric pits. CRS, cold restraint stress; Neb, nebivolol; Ran, ranitidine; RS, cold restraint stress; Sim, simvastatin. Scale bars $=100 \mu \mathrm{m}(\mathrm{A}-\mathrm{F})$. 

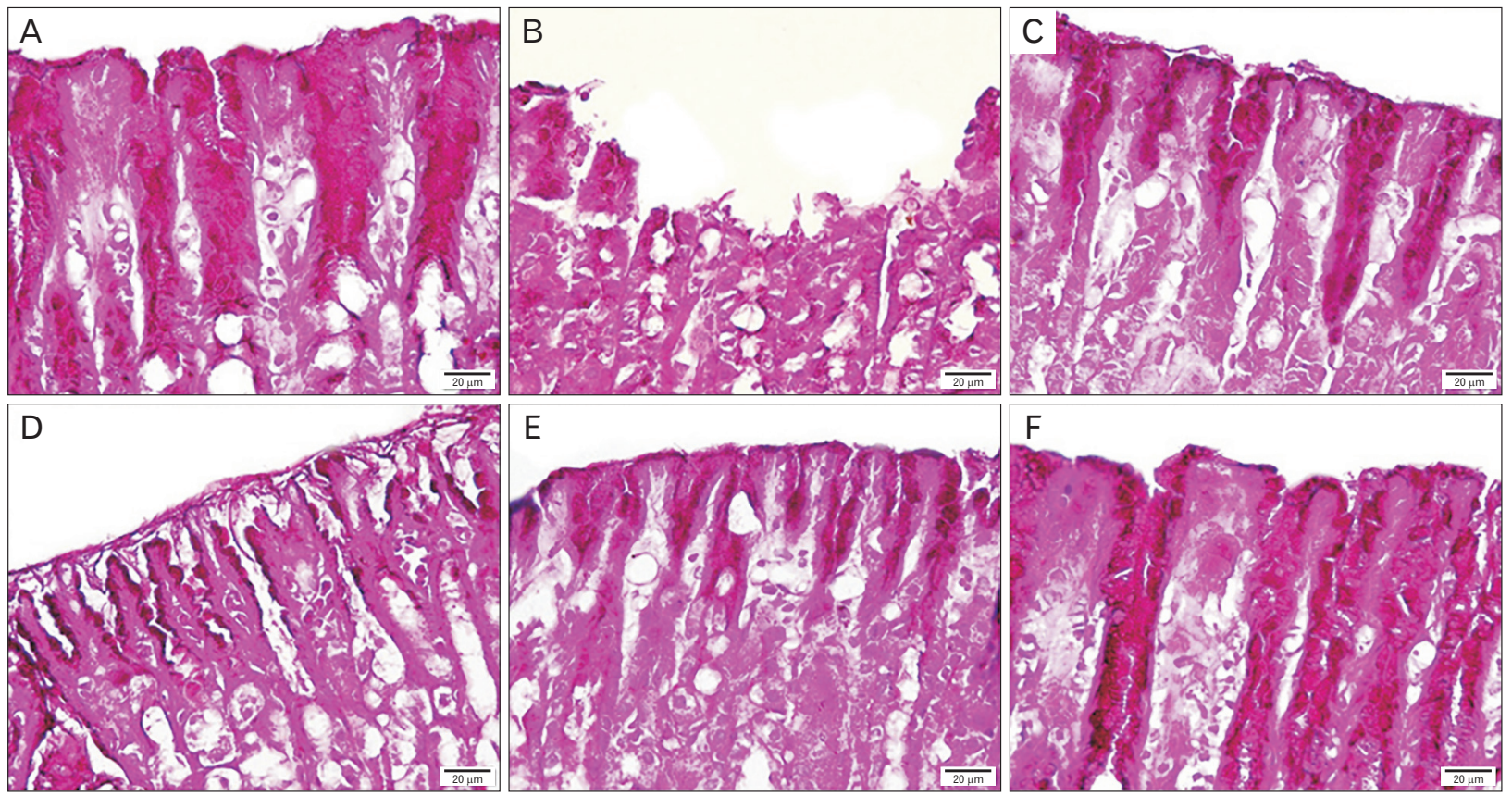

Fig. 4. Photomicrograph of PAS stained sections in gastric mucosa $(\times 400)$ showing: (A) Control group: continuous strong PAS+ve reaction in the surface and neck region of the gastric glands. (B) CRS: mucosal abrasion with alternating absent to few PAS+ve reaction. (C) Ran+CRS: continuous strong PAS+ve reaction. (D) Sim+CRS: preserved PAS+ve reaction. (E) Neb+CRS: preserved PAS+ve reaction. (F) Sim+Neb+CRS: marked increase in the mucosal PAS+ve reaction. CRS, cold restraint stress; Neb, nebivolol; PAS, periodic acid Schiff's; Ran, ranitidine; Sim, simvastatin. Scale bars $=20 \mu \mathrm{m}(\mathrm{A}-\mathrm{F})$.

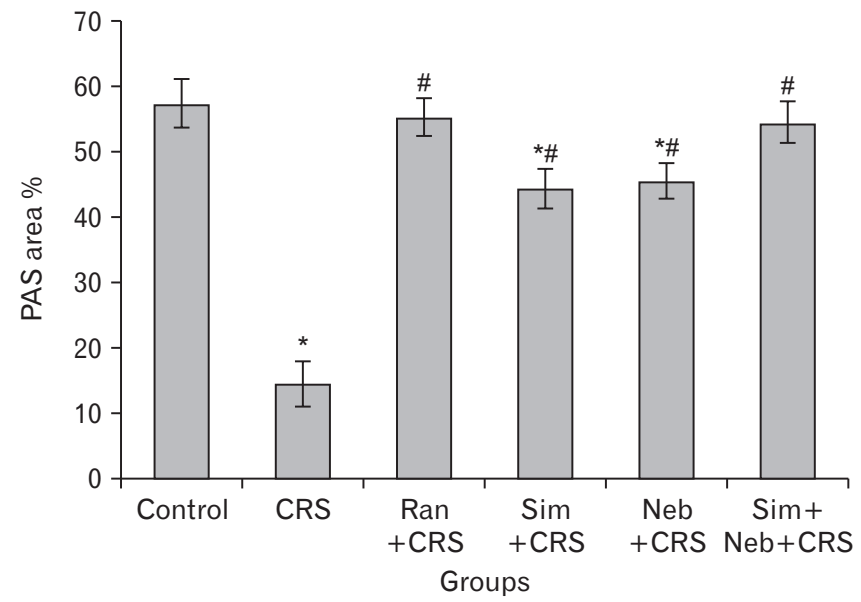

Fig. 5. Quantification analysis of the mean PAS+ve area \%. CRS, cold restraint stress; Neb, nebivolol; PAS, periodic acid Schiff's; Ran, ranitidine; Sim, simvastatin. *Significant decrease $(P<0.05)$ when compared with control. ${ }^{*}$ Significant increase $(P<0.05)$ when compared with CRS.

\section{Immunohistochemical evaluation of COX-2 in gastric mucosa}

Minimal detection of COX-2+ve immunostaining was observed in the control gastric mucosa. In CRS, minimal COX-2+ve immunostaining was detected at the edge of the ulcer with negative immunostaining at the base of the ulcer. Ran pretreatment induced significant augmentation of COX-2+ve immunostaining in gastric mucosa as compared to CRS group. Pretreatment with Sim or Neb illustrated moderate COX-2+ve immunostaining. However, Sim+Neb+CRS displayed substantial increase in COX-2+ve immunostaining in gastric mucosa as compared to CRS, Sim+CRS and Neb+CRS groups (Fig. 6, 7).

\section{Discussion}

The results of the present study showed that exposure to CRS in rats resulted in severe mucosal ulceration associated with significant increase in MDA and, significant reduction in gastric mucosal GSH, $\mathrm{NO}$, and $\mathrm{PGE}_{2}$.

Kwiecien et al. [32] and Brzozowski et al. [33] reported that the cold-restraint stress model in rats mimics clinical acute gastric lesions, that may appear in the gastric mucosa as a consequence of major trauma, surgery or sepsis and it is widely accepted for studying the mechanism of stress induced gastric lesions.

In the present study, pretreatment with $\mathrm{Neb}$ and Sim 

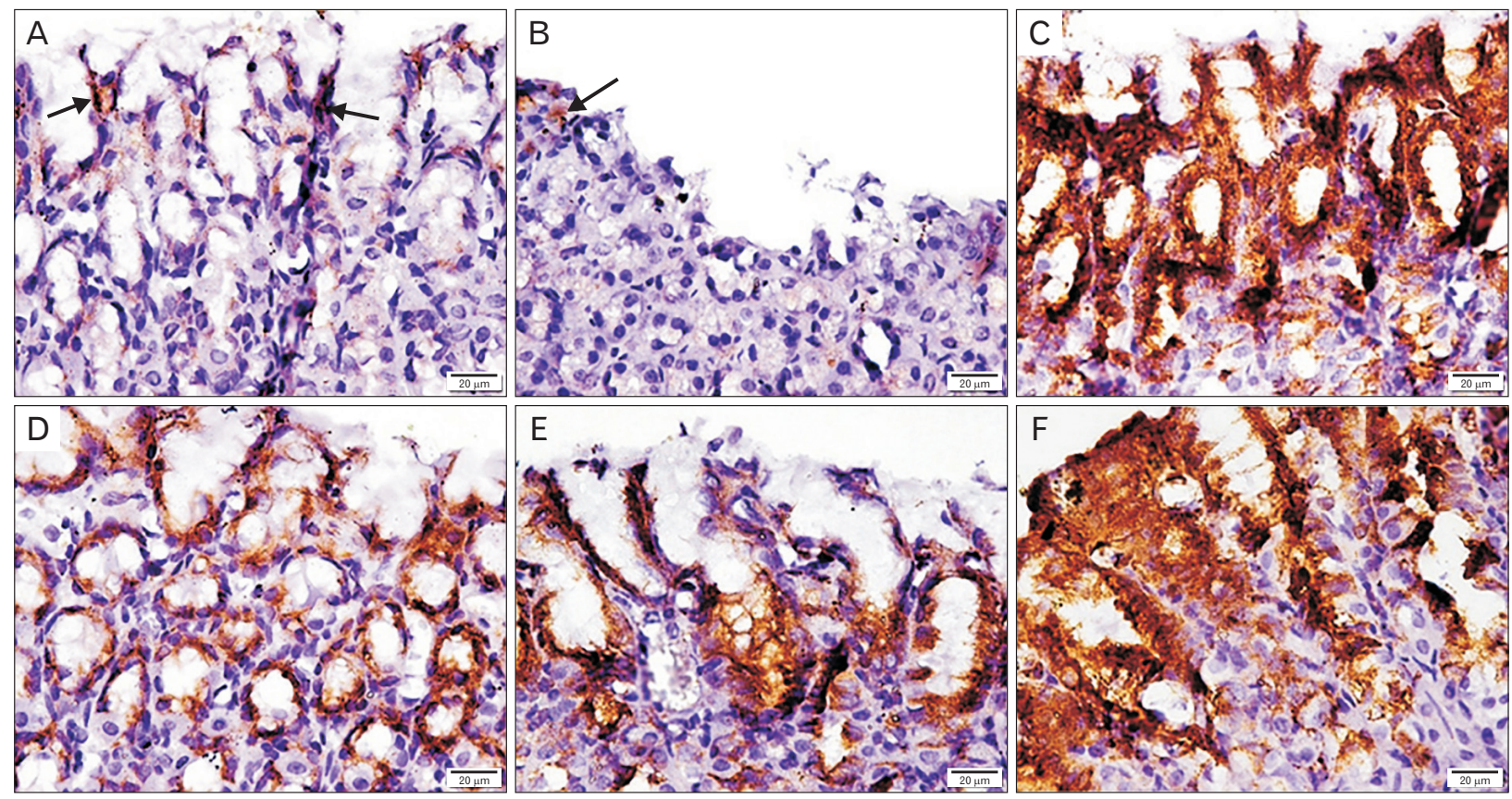

Fig. 6. Photomicrograph of COX-2 immunostaining ( $\times 400)$ showing: (A) Control group: minimal COX-2+ve immunostaining in gastric mucosa. (B) CRS: minimal+ve immunostaining at the edge of the ulcer. (C) Ran+CRS: enhanced COX-2+ve immunostaining in the glandular epithelium and stromal cells. (D) Sim+CRS: moderate COX-2+ve immunostaining in the gastric mucosa. (E) Neb+CRS: moderate COX$2+\mathrm{ve}$ immunostaining in the gastric mucosa. (F) Sim+Neb+CRS: marked increase COX-2+ve immunostaining in gastric mucosa. COX-2, cyclooxygenase 2; CRS, cold restraint stress; Neb, nebivolol; PAS, periodic acid Schiff's; Ran, ranitidine; Sim, simvastatin. Scale bars=20 $\mu$ m (AF).

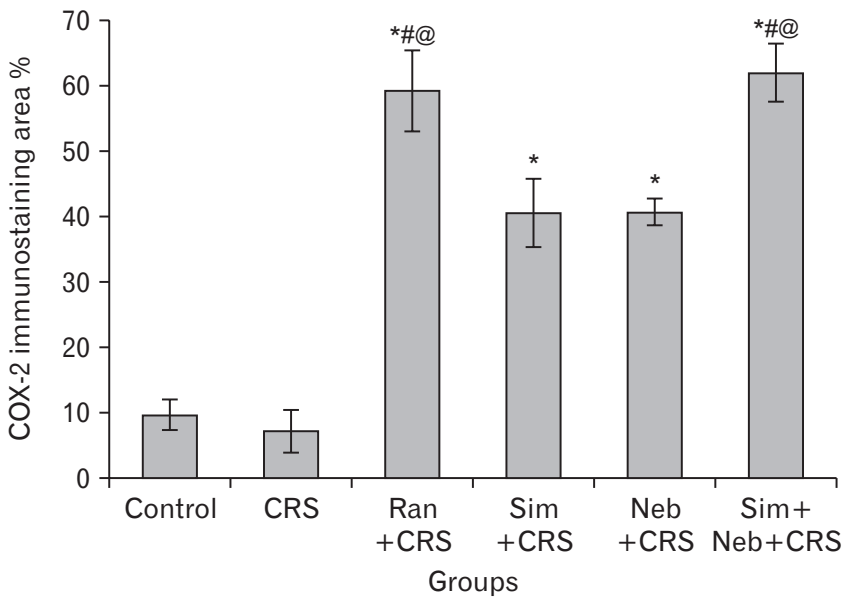

Fig. 7. Quantification analysis of the mean COX-2+ve immunostaining area \%. COX-2, cyclooxygenase 2; CRS, cold restraint stress; Neb, nebivolol; Ran, ranitidine; Sim, simvastatin. * ${ }^{*}$ ignificant increase $(P<0.05)$ when compared with control and CRS groups. "Significant increase $(P<0.05)$ when compared with Sim+CRS, ${ }^{\circledR}$ Significant increase $(P<0.05)$ when compared with Neb+CRS groups.

significantly protected rats from CRS-induced gastric ulceration; they significantly reduced gastric mucosal MDA level with concomitant increase in the GSH and $\mathrm{PGE}_{2}$ and NO.
The results of the present study are in accordance with Haendeler et al. [34] who showed that Sim pretreatment caused significant reduction in MDA level in both ulcer models as compared to non-treated control groups and it was reported that Sim possesses free radicals scavenger activity. This suggests that Sim afforded part of its gastroprotective effect in both ulcer models via antioxidant activity. Tariq et al. [35] also demonstrated that oral administration of Sim in doses of $20,40,60 \mathrm{mg} / \mathrm{kg}$ for 7 days significantly and dose dependently reduced gastric lesions induced by indomethacin and ethanol in rats, an effect accompanied by reduction in total acidity and volume of gastric juice.

Moreover, Matsui et al. [36] have shown that rats pretreated with Sim showed significant increase in $\mathrm{PGE}_{2}$ level. PGs also play an essential role in gastric mucosal defense. This effect is dependent on the PG-induced stimulation of bicarbonate and mucous secretion, inhibition of gastric acid secretion, and regulation of maintaining epithelial cell restitution and mucosal blood flow. Furthermore, Bjarnason et al. [37] reported marked elevation of nitrite level in CRS while Sim was able to normalize the nitrite levels, it deceased NO level in CRS group. Stress ulcer increases the formation of reactive 
oxygen metabolites and promotes inhibition of PG synthesis, leading to alterations in gastric NO levels.

$\mathrm{NO}$ is a double-edged weapon exerting either protective or destructive effects depending on the extent of NO synthesis Tariq et al. [35]. It has been reported that NO generated from constitutive NOS (cNOS) plays an important role in gastric ulcer formation and healing [38] and considered to be beneficial in maintaining the mucosal integrity [39], whereas NO generated from inducible nitric oxide synthase (iNOS) participates in ulcer formation through the production of oxygen derived radical and their cytotoxic actions [40]. This suggests that NO production from iNOS may play a detrimental role in stress-induced gastric injuries. The present work showed a marked reduction in nitrite levels (an iNOS) in the simvatstin pre-treated group, a change not observed in the Ran pre-treated group. These findings can be attributed to the ability of simvatstin to downregulate the iNOS mRNA expression leading to decreased production of gastric mucosal NO. The nitrite levels is markedly elevated, which could be occurring due to stimulation of iNOS, which reacts with superoxide to form peroxynitrite, a potent cytotoxic oxidant causing gastric damage [41].

In this study, Neb-induced a significant increase in GSH which is in accordance with the findings of Goel et al. [42] who reported that chronic administration of Neb shows significant increase in brain GSH level. Ceron et al. [43] also demonstrated that Neb attenuated the vascular remodeling associated with increased oxidative stress in hypertensive rats. Moreover, Rizzi et al. [44] found evidence that Neb as a selective $\beta 1$-blocker with antioxidant properties attenuates hypertensioninduced left ventricular hypertrophy and cardiac collagen deposition in association with significant cardiac antioxidant effects in rats.

Furthermore, Dursun et al. [45] reported that Neb showed an antioxidant effect besides its low density lipoprotein lowering effect in a rat model of N-nitroL-arginine methyl ester-induced oxidative stress, vascular inflammation, and arteriosclerosis.

Uzar et al. [46] reported that Neb was shown to prevent oxidative stress in rats with ischemia-induced cerebral injury. Whaley-Connell et al. [47] also have shown that Neb may reduce oxidative stress in skeletal muscle tissue by reducing both NADPH oxidase and mitochondrial generation of ROS.

Omaima and Abeer [48] found that Neb induced significant decrease in iNOS expression and mucosal nitrite/nitrate levels compared to indomethacin administered rats, this may be attributed in part to the increased consumption of NO in free radical scavenging, hindering lipid peroxidation and to the stimulation of cNOS in gastric tissue which produce a low concentration of cytoprotective NO. These data depict the involvement of NO pathway in anti-ulcerogenic potential of Neb. Several reports have demonstrated the NO-mediated beneficial effects of Neb on different tissues. Neb has been shown to produce NO-mediated relaxation of the rat mesenteric vascular bed and increase cNOS activity in cultured bovine coronary postcapillary endothelial cells [49]. Neb has also been found to induce relaxation of rat renal glomerular vasculature by increasing NO release [50]. Another study by Zhou et al., [51] demonstrated that the vasodilatory and anti-oxidant properties of $\mathrm{Neb}$ are likely through reduction in NADPH oxidase activity and enhancement of endothelial NO synthase activity. Besides, it has been reported that $\mathrm{Neb}$ treatment leads to reductions in NADPH oxidase activity in the heart and vascular tissue [11]. A study by Manrique et al. [52], has highlighted that Neb induced improvement in insulin metabolic signaling and enhancement in bioavailable NO in skeletal muscle. Other than the important role of $\mathrm{NO}$ in maintenance of blood flow, it may protect against indomethacin-induced gastric damage by promotion of PGs synthesis. PGs, especially $\mathrm{PGE}_{2}$, modulate a number of components of mucosal defense as they stimulate mucus and bicarbonate secretion, increase mucosal blood flow, increase the resistance of epithelial cells to cytotoxins-induced injury and suppress the recruitment of leukocytes into gastric mucosa. PGs can also down regulate the release of other inflammatory mediators that may contribute to the generation of gastric ulcer. $\mathrm{PGE}_{2}$ has been shown to be a potent inhibitor of TNF- $\alpha$ and IL-1 release from macrophages and of leukotriene B4 and IL-8 release from neutrophils [53].

Histological analysis of gastric mucosa of CRS group revealed mucosal erosions and hemorrhagic ulcers with significant decrease in the mucus production indicating affection of the mucosal defense of the stomach. Similar results were documented by Vaseem et al. [54]. Many factors have been postulated in the development of stress peptic ulcer, as inadequate blood microcirculation with following tissue hypoxemia and oxidative stress [23] and increasing the acid secretion with reduction in mucus secretion [55].

Combined administration of Sim and Neb pretreatment substantially protected the gastric mucosa and augmented the mucosal PAS+ve reaction as compared to Ran. However, pretreatment with either Sim or Neb alone provided signifi- 
cant protection of gastric mucosa, but it was less comparable to Ran. Sim, a commonly prescribed statin, was documented as anti-inflammatory, antioxidant effect and immunomodulatory agent [56]. Additional benefits of Sim included gastroprotective effects and amelioration of peptic ulcer. It was found to enhance gastric mucosal defense against indomethacin-induced gastric ulceration via increasing $\mathrm{NO}$ and $\mathrm{PGE}_{2}$ levels, promoting gastric mucin release and providing antioxidant activity [57]. Recent evidences concluded that statin mitigate Helicobacter pylori-associated pathogenesis [58] and protect against peptic ulcer in patients [59]. Neb has pleiotropic effects as being vasodilator and anti-oxidative which provides preferable protection from gastric ulcer [23]. It has been reported that Neb significantly reduces MDA, tumor necrosis factor- $\alpha$, and interleukin-1beta in indomethacin-induced gastric ulcer due to its anti-oxidant activity [48].

The present study showed minimal detection of COX$2+$ ve immunostaining, in gastric mucosa of CRS group at the gastric ulcer margin. Meanwhile, combined Sim and Neb pretreatment exhibited marked COX-2+ve immunostaining in the surface and glandular gastric epithelium. COX enzyme plays pivotal role in PG synthesis. It exists in 2 isoforms: COX-1 and COX-2. COX-1 is constitutively expressed in most of tissues and mediates PG synthesis needed for physiological functions. COX-2 and PG can induce angiogenesis and heavy infiltration of macrophages and reconstruct the inflammatory microenvironment [60].

COX-2 is normally undetectable in most tissues but substantially inducible as a compensatory mechanism to enhance PG synthesis during pathological conditions [23]. It promotes cell survival, cell proliferation and angiogenesis [61]. It was postulated that COX-2 expression at the ulcer margins is a trial for healing; however continuous inhibition of COX-2 activity delays the healing process [62]. Statins was documented to up-regulate the expression of COX-2 in human vascular smooth muscle cells. Moreover, Neb pretreatment was found to increase the level of NO which increases the activity of COX-2 enzyme. Several studies have reported cross talk between NO and COX-2 in contribution to gastric defense mechanisms [63].

The combination of beta blockers as Neb and statins as Sim has revealed a beneficial effect in previous study by Rizos et al. [64]. The Neb decrease the serum high sensitivity C-reactive protein and increase the homocysteine level while insulin levels and the homeostatic model assessment index were reduced. Adding statins is useful as protective against the stress effect as it decrease level of cholesterol, Low density lipoprotein and apoproteins. Moreover, homocysteine levels and C-reactive protein were also reduced [64].

Our work showed that Neb and Sim reversed all the deleterious effects induced by CRS on gastric mucosa.

In conclusion, it could be concluded from the results of the present study that both Neb and Sim have gastroprotective effect against CRS induced gastric ulcer in rats. The mechanism could be attributed to their NO releasing property and inhibitory effect on oxidative stress as evident from their antioxidant activity.

\section{ORCID}

\author{
Samaa Samir Kamar: \\ https://orcid.org/0000-0002-9040-584X \\ Noha Samir Abdel Latif: \\ https://orcid.org/0000-0003-4248-9775 \\ Mohamed Fathi Mohamed Elrefai: \\ https://orcid.org/0000-0002-4442-9867 \\ Shaimaa Nasr Amin: \\ https://orcid.org/0000-0001-9232-2389
}

\section{Author Contributions}

Conceptualization: SSK, NSAL, SNA. Data acquisition: SSK, NSAL, MFME, SNA. Data analysis or interpretation: SNA. Drafting of the manuscript: SSK, NSAL, MFME, SNA. Critical revision of the manuscript: SNA. Approval of the final version of the manuscript: all authors.

\section{Conflicts of Interest}

No potential conflict of interest relevant to this article was reported.

\section{Acknowledgements}

We would like to thank Prof. Dr. Laila Ahmed Rashed, professor of biochemistry for her kind help in biochemical measurements. We would like also to thank technicians at pharmacology and physiology department for their kind help in this work. 


\section{References}

1. Khazaei M, Salehi H. Protective effect of falcaria vulgaris extract on ethanol induced gastric ulcer in rat. Iran J Pharmacol Ther 2006;5:43-6.

2. Bayir Y, Odabasoglu F, Cakir A, Aslan A, Suleyman H, Halici M, Kazaz C. The inhibition of gastric mucosal lesion, oxidative stress and neutrophil-infiltration in rats by the lichen constituent diffractaic acid. Phytomedicine 2006;13:584-90.

3. Bonamin F, Moraes TM, Dos Santos RC, Kushima H, Faria FM, Silva MA, Junior IV, Nogueira L, Bauab TM, Souza Brito AR, da Rocha LR, Hiruma-Lima CA. The effect of a minor constituent of essential oil from Citrus aurantium: the role of $\beta$-myrcene in preventing peptic ulcer disease. Chem Biol Interact 2014;212:11-9.

4. Lima ZP, Severi JA, Pellizzon CH, Brito AR, Solis PN, Cáceres A, Girón LM, Vilegas W, Hiruma-Lima CA. Can the aqueous decoction of mango flowers be used as an antiulcer agent? J Ethnopharmacol 2006;106:29-37.

5. Valle JD. Peptic ulcer disease and related disorders. In: Fauci AS, Harrison TR, editors. Harrison's principles of internal medicine. 17th ed. New York: McGraw-Hill; 2008. p.1855-1872.

6. Dimaline R, Varro A. Attack and defence in the gastric epithelium- a delicate balance. Exp Physiol 2007;92:591-601.

7. Yeomans ND. The ulcer sleuths: the search for the cause of peptic ulcers. J Gastroenterol Hepatol 2011;26 Suppl 1:35-41.

8. Wallace JL, Miller MJ. Nitric oxide in mucosal defense: a little goes a long way. Gastroenterology 2000;119:512-20.

9. Ohta Y, Nishida K. Protective effect of coadministered superoxide dismutase and catalase against stress-induced gastric mucosal lesions. Clin Exp Pharmacol Physiol 2003;30:545-50.

10. Aragón JP, Condit ME, Bhushan S, Predmore BL, Patel SS, Grinsfelder DB, Gundewar S, Jha S, Calvert JW, Barouch LA, Lavu M, Wright HM, Lefer DJ. Beta3-adrenoreceptor stimulation ameliorates myocardial ischemia-reperfusion injury via endothelial nitric oxide synthase and neuronal nitric oxide synthase activation. J Am Coll Cardiol 2011;58:2683-91.

11. Sorrentino SA, Doerries C, Manes C, Speer T, Dessy C, Lobysheva I, Mohmand W, Akbar R, Bahlmann F, Besler C, Schaefer A, Hilfiker-Kleiner D, Lüscher TF, Balligand JL, Drexler $\mathrm{H}$, Landmesser U. Nebivolol exerts beneficial effects on endothelial function, early endothelial progenitor cells, myocardial neovascularization, and left ventricular dysfunction early after myocardial infarction beyond conventional $\beta 1$-blockade. J Am Coll Cardiol 2011;57:601-11.

12. Fonseca VA. Effects of beta-blockers on glucose and lipid metabolism. Curr Med Res Opin 2010;26:615-29.

13. Corsini A, Maggi FM, Catapano AL. Pharmacology of competitive inhibitors of HMG-CoA reductase. Pharmacol Res 1995;31:9-27.

14. Liao JK. Effects of statins on 3-hydroxy-3-methylglutaryl coenzyme a reductase inhibition beyond low-density lipoprotein cholesterol. Am J Cardiol 2005;96(5A):24F-33F.
15. Trochu JN, Mital S, Zhang Xp, Xu X, Ochoa M, Liao JK, Recchia FA, Hintze TH. Preservation of NO production by statins in the treatment of heart failure. Cardiovasc Res 2003;60:250-8.

16. Schrör K, Löbel P, Steinhagen-Thiessen E. Simvastatin reduces platelet thromboxane formation and restores normal platelet sensitivity against prostacyclin in type IIa hypercholesterolemia. Eicosanoids 1989;2:39-45.

17. Ungureanu D, Filip C, Artenie A, Artenie R. Evaluation of simvastatin antioxidant effects. Rev Med Chir Soc Med Nat Iasi 2003;107:66-71.

18. Institute for Laboratory Animal Research; National Academies Press. Guide for the care and use of laboratory animals. 8th ed. Washington: National Academies Press; 2011. 220 p.

19. Dronjak S, Gavrilović L, Filipović D, Radojcić MB. Immobilization and cold stress affect sympatho-adrenomedullary system and pituitary-adrenocortical axis of rats exposed to longterm isolation and crowding. Physiol Behav 2004;81:409-15.

20. Das D, Banerjee RK. Effect of stress on the antioxidant enzymes and gastric ulceration. Mol Cell Biochem 1993;125:11525.

21. Bahgat AK. Gastroprotective effect of L-carnitine on indomethacin-induced gastric ulcer in rats: the involvement of antioxidant mechanisms and nitric oxide. Med J Cairo Univ 2009;77:43-51.

22. Abd El Motteleb DM, Hasan MM. Gastroprotective effect of simvastatin against experimentally induced gastric ulcers in rats: role of ATP-sensitive K+ channels. J Am Sci 2011;7:760-8.

23. Morsy MA, Heeba GH, Abdelwahab SA, Rofaeil RR. Protective effects of nebivolol against cold restraint stress-induced gastric ulcer in rats: role of NO, HO-1, and COX-1,2. Nitric Oxide 2012;27:117-22.

24. Vane JR. A sensitive method for the assay of 5-hydroxytryptamine. Br J Pharmacol Chemother 1957;12:344-9.

25. Ohkawa H, Ohishi N, Yagi K. Assay for lipid peroxides in animal tissues by thiobarbituric acid reaction. Anal Biochem 1979;95:351-8.

26. Ellman GL. Tissue sulfhydryl groups. Arch Biochem Biophys 1959;82:70-7.

27. Habig WH, Pabst MJ, Jakoby WB. Glutathione S-transferases. The first enzymatic step in mercapturic acid formation. J Biol Chem 1974;249:7130-9.

28. Hamberg M, Samuelsson B. Detection and isolation of an endoperoxide intermediate in prostaglandin biosynthesis. Proc Natl Acad Sci U S A 1973;70:899-903.

29. Miranda KM, Espey MG, Wink DA. A rapid, simple spectrophotometric method for simultaneous detection of nitrate and nitrite. Nitric Oxide 2001;5:62-71.

30. Zhang H, Li X, Ding J, Xu H, Dai X, Hou Z, Zhang K, Sun K, Sun W. Delivery of ursolic acid (UA) in polymeric nanoparticles effectively promotes the apoptosis of gastric cancer cells through enhanced inhibition of cyclooxygenase 2 (COX-2). Int J Pharm 2013;441:261-8.

31. Altman GD. Three or more independent groups of observations. In: Altman DG, editor. Practical statistics for medical 
research. 2nd ed. London: Chapman \& Hall; 2005. p.205-17.

32. Kwiecień S, Brzozowski T, Konturek SJ. Effects of reactive oxygen species action on gastric mucosa in various models of mucosal injury. J Physiol Pharmacol 2002;53:39-50.

33. Brzozowski T, Konturek PC, Pajdo R, Ptak-Belowska A, Kwiecien S, Pawlik M, Drozdowicz D, Sliwowski Z, Brzozowski B, Konturek SJ, Pawlik WW. Physiological mediators in nonsteroidal anti-inflammatory drugs (NSAIDs)-induced impairment of gastric mucosal defense and adaptation. Focus on nitric oxide and lipoxins. J Physiol Pharmacol 2008;59 Suppl 2:89-102.

34. Haendeler J, Hoffmann J, Zeiher AM, Dimmeler S. Antioxidant effects of statins via S-nitrosylation and activation of thioredoxin in endothelial cells: a novel vasculoprotective function of statins. Circulation 2004;110:856-61.

35. Tariq M, Khan HA, Elfaki I, Arshaduddin M, Al Moutaery M, Al Rayes H, Al Swailam R. Gastric antisecretory and antiulcer effects of simvastatin in rats. J Gastroenterol Hepatol 2007;22:2316-23.

36. Matsui H, Shimokawa O, Kaneko T, Nagano Y, Rai K, Hyodo I. The pathophysiology of non-steroidal anti-inflammatory drug (NSAID)-induced mucosal injuries in stomach and small intestine. J Clin Biochem Nutr 2011;48:107-11.

37. Bjarnason I, Scarpignato C, Takeuchi K, Rainsford KD. Determinants of the short-term gastric damage caused by NSAIDs in man. Aliment Pharmacol Ther 2007;26:95-106.

38. Ma L, Wallace JL. Endothelial nitric oxide synthase modulates gastric ulcer healing in rats. Am J Physiol Gastrointest Liver Physiol 2000;279:G341-6.

39. Kato S, Ohkawa F, Ito Y, Amagase K, Takeuchi K. Role of endothelial nitric oxide synthase in aggravation of indomethacininduced gastric damage in adjuvant arthritic rats. J Physiol Pharmacol 2009;60:147-55.

40. Cho $\mathrm{CH}$. Current roles of nitric oxide in gastrointestinal disorders. J Physiol Paris 2001;95:253-6.

41. Lanas A. Role of nitric oxide in the gastrointestinal tract. Arthritis Res Ther 2008;10(Suppl 2):S4.

42. Goel R, Goel A, Manocha A, Pillai KK, Srivastava RS. Influence of nebivolol on anticonvulsant effect of lamotrigine. Indian J Pharmacol 2009;41:41-6.

43. Ceron CS, Rizzi E, Guimarães DA, Martins-Oliveira A, Gerlach RF, Tanus-Santos JE. Nebivolol attenuates prooxidant and profibrotic mechanisms involving TGF- $\beta$ and MMPs, and decreases vascular remodeling in renovascular hypertension. Free Radic Biol Med 2013;65:47-56.

44. Rizzi E, Guimaraes DA, Ceron CS, Prado CM, Pinheiro LC, Martins-Oliveira A, Gerlach RF, Tanus-Santos JE. $\beta 1$ Adrenergic blockers exert antioxidant effects, reduce matrix metalloproteinase activity, and improve renovascular hypertension-induced cardiac hypertrophy. Free Radic Biol Med 2014;73:308-17.

45. Dursun S, Çuhadar S, Köseoğlu M, Atay A, Aktaş SG. The anti-inflammatory and antioxidant effects of pravastatin and nebivolol in rat aorta. Anadolu Kardiyol Derg 2014;14:229-33.
46. Uzar E, Acar A, Evliyaoğlu O, Fırat U, Kamasak K, Göçmez C, Alp H, Tüfek A, Taşdemir N, Ilhan A. The anti-oxidant and anti-apoptotic effects of nebivolol and zofenopril in a model of cerebral ischemia/reperfusion in rats. Prog Neuropsychopharmacol Biol Psychiatry 2012;36:22-8.

47. Whaley-Connell A, Habibi J, Johnson M, Tilmon R, Rehmer N, Rehmer J, Wiedmeyer C, Ferrario CM, Sowers JR. Nebivolol reduces proteinuria and renal NADPH oxidase-generated reactive oxygen species in the transgenic Ren 2 rat. Am J Nephrol 2009;30:354-60.

48. Abd Allah OM, Sharaf El-Din AAI. Nebivolol ameliorates indomethacin-induced gastric ulcer in adult albino rats: role of inducible nitric oxide synthase. Egypt J Forensic Sci Appli Toxicol 2016;16:147-67.

49. Parenti A, Filippi S, Amerini S, Granger HJ, Fazzini A, Ledda F. Inositol phosphate metabolism and nitric-oxide synthase activity in endothelial cells are involved in the vasorelaxant activity of nebivolol. J Pharmacol Exp Ther 2000;292:698-703.

50. Kalinowski L, Dobrucki LW, Szczepanska-Konkel M, Jankowski M, Martyniec L, Angielski S, Malinski T. Third-generation beta-blockers stimulate nitric oxide release from endothelial cells through ATP efflux: a novel mechanism for antihypertensive action. Circulation 2003;107:2747-52.

51. Zhou X, Ma L, Habibi J, Whaley-Connell A, Hayden MR, Tilmon RD, Brown AN, Kim JA, Demarco VG, Sowers JR. Nebivolol improves diastolic dysfunction and myocardial remodeling through reductions in oxidative stress in the Zucker obese rat. Hypertension 2010;55:880-8.

52. Manrique C, Lastra G, Habibi J, Pulakat L, Schneider R, Durante W, Tilmon R, Rehmer J, Hayden MR, Ferrario CM, Whaley-Connell A, Sowers JR. Nebivolol improves insulin sensitivity in the TGR(Ren2)27 rat. Metabolism 2011;60:1757-66.

53. Martin GR, Wallace JL. Gastrointestinal inflammation: a central component of mucosal defense and repair. Exp Biol Med (Maywood) 2006;231:130-7.

54. Vaseem A, Ali M, Afshan K. Activity of Tulsi leaves (Ocimum sanctum linn) in protecting gastric ulcer in rats by cold restrain method. Int J Basic Clin Pharmacol 2017;6:2343-7.

55. Godara R, Katoch R, Yadav A, Ahanger RR, Bhutyal AD, Verma PK, Katoch M, Dutta S, Nisa F, Singh NK. In vitro acaricidal activity of ethanolic and aqueous floral extracts of Calendula officinalis against synthetic pyrethroid resistant Rhipicephalus (Boophilus) microplus. Exp Appl Acarol 2015;67:147-57.

56. Banfi C, Baetta R, Gianazza E, Tremoli E. Technological advances and proteomic applications in drug discovery and target deconvolution: identification of the pleiotropic effects of statins. Drug Discov Today 2017;22:848-69.

57. Heeba GH, Hassan MK, Amin RS. Gastroprotective effect of simvastatin against indomethacin-induced gastric ulcer in rats: role of nitric oxide and prostaglandins. Eur J Pharmacol 2009;607:188-93.

58. Liao WC, Huang MZ, Wang ML, Lin CJ, Lu TL, Lo HR, Pan YJ, Sun YC, Kao MC, Lim HJ, Lai CH. Statin decreases Helicobacter pylori burden in macrophages by promoting autophagy. 
Front Cell Infect Microbiol 2017;6:203.

59. Lin CJ, Liao WC, Chen YA, Lin HJ, Feng CL, Lin CL, Lin YJ, Kao MC, Huang MZ, Lai CH, Kao CH. Statin therapy is associated with reduced risk of peptic ulcer disease in the Taiwanese population. Front Pharmacol 2017;8:210.

60. Han ME, Oh SO. Gastric stem cells and gastric cancer stem cells. Anat Cell Biol 2013;46:8-18.

61. Elwood PC, Gallagher AM, Duthie GG, Mur LA, Morgan G. Aspirin, salicylates, and cancer. Lancet 2009;373:1301-9.

62. Warzecha Z, Ceranowicz P, Dembinski M, Cieszkowski J, Ginter G, Ptak-Belowska A, Dembinski A. Involvement of cyclooxygenase- 1 and cyclooxygenase- 2 activity in the therapeutic effect of ghrelin in the course of ethanol-induced gastric ulcers in rats. J Physiol Pharmacol 2014;65:95-106.

63. El-Ashmawy NE, Khedr EG, El-Bahrawy HA, Selim HM. Nebivolol prevents indomethacin-induced gastric ulcer in rats. J Immunotoxicol 2016;13:580-9.

64. Rizos E, Bairaktari E, Kostoula A, Hasiotis G, Achimastos A, Ganotakis E, Elisaf M, Mikhailidis DP. The combination of nebivolol plus pravastatin is associated with a more beneficial metabolic profile compared to that of atenolol plus pravastatin in hypertensive patients with dyslipidemia: a pilot study. J Cardiovasc Pharmacol Ther 2003;8:127-34. 